\title{
Hubungan Antara Keaktifan Berorganisasi Dengan Tingkat Perilaku Prososial Mahasiswa Pengurus PMII UNNES Tahun 2020
}

\author{
Muchammad Badaruddin, Anwar Sutoyo \\ Jurusan Bimbingan dan Konseling, Fakultas Ilmu Pendidikan
}

\begin{abstract}
Fakultas Ilmu Pendididkan
\end{abstract}
Universitas Negeri Semarang

\begin{abstract}
Abstrak
Berdasarkan fenomena yang ada dalam organisasi mahasiswa PMII UNNES ditemukan bahwa perilaku prososial mahasiswa pengurus PMII UNNES sudah baik, namun terdapat pengurus dengan tingkat perilaku prososial yang rendah yang dilakukan ketika diluar organisasi. Penelitian ini bertujuan untuk mengetahui hubungan antara keaktifan berorganisasi dengan tingkat perilaku prososial. Teknik yang digunakan dalam pengambilan data dalam penelitian ini adalah Teknik sampling jenuh. Dalam penelitian ini sampelnya adalah seluruh mahasiswa pengurus PMII UNNES tahun 2020 yang berjumlah 63 mahasiswa. Pengumpulan data dilakukakn dengan cara pre-test dan post-test dengan menggunakan skala keaktifan berorganisasi dan skala prososial. Jenis penelitian dalam penelitian ini adalah kuantitatif korelasional dengan menggunakan rumus korelasi product moment yang dikemukakan oleh Karl Pearson yaitu rumus Pearson Correlation. Hasil penelitian menghasilkan koefisien korelasi $(r)=0,512$ dan $p=0,915>0,05$ yang menunjukkan bahwa ada hubungan positif dan signifikan antara keaktifan berorganisasi dengan tingkat perilaku prososial mahasiswa pengurus PMII UNNES tahun 2020.
\end{abstract}

Kata Kunci: Perilaku Prososial, Keaktifan Berorganisasi, Mahasiswa

\begin{abstract}
Based on the phenomenon that exists in the PMII UNNES student organization, it was found that the prosocial behavior of the members of PMII UNNES was good, but some of the administrators had low level of prosocial behavior when it comes in the outside of the organization. This research aims to determine the relationship between organizational contribution with the level of prosocial behavior. The technique used to collect the data is jenuh sampling. 63 members of the PMII UNNES year 2020 were the sample of this study. The data was collected by doing a pre-test and post-test using the organizational contribution scale and the prosocial scale. This research used correlational quantitative method with the correlation formula of 'product moment' named Pearson Correlation proposed by Karl Pearson. The result showed that the correlation coefficient $(r)=0.512$ and $p=0.915>0.05$, which indicates that there is a positive and significant relationship between organizational contribution and the level of prosocial behavior done by the members of PMII UNNES year 2020 .
\end{abstract}

Keywords: Prosocial Behavior, Organizational Activeness, Students 


\section{PENDAHULUAN}

Manusia merupakan makhluk social yang hidup membutuhkan bantuan orang lain dalam menjalankan kehidupannya. Memberikan bantuan kepada orang lain juga merupakan salah satu bentuk perilaku prososial. Mahmudah (2010:85) menjelaskan bahwa perilaku prososial tidak lepas dari kehidupan manusia dalam interaksinya dalam masyarakat. Dengan kata lain dalam interaksi bermasyarakat manusia tidak akan lepas dari perbuatan perilaku tolong menolong.

Dayakisini \& Hudaniah (2015:162) mengemukakan bahwa perilaku prososial adalah segala bentuk perilaku yang memberikan konsekwensi positif bagi penerima, baik dalam bentuk materi, fisik ataupun psikologis, akan tetapi tidak memiliki keuntungan yang jelas bagi pemiliknya. Perilaku prososial merupakan bentuk tindakan yang baik dan positif, dilakukan secara sukarela atas kemauan sendiri, dilakukan sematamata hanya untuk membantu dan menolong orang lain tanpa harapan ingin diberikan timbal balik. Adapun aspek-aspek yang dalam perilaku prososial adalah berbagi, kerjasama, menyumbang, menolong, jujur, dan dermawan.

Perilaku prososial sangat penting ditingkatkan kepada mahasiswa, hal ini beralaskan bahwa mahasiswa yang sejatinya adalah harapan yang akan memberikan perubahan masyarakat bisa secara maksimal membawa perubahan kearah positif. Adapun faktor-faktor yang mempengaruhi perilaku prososial menurut Baron dan Branscombe (2012:301) diantaranya adalah factor kesamaan dan tanggung jawab, pengaruh model prososial secara langsung, video game, rasa bersyukur.

Kampus sebagai salah satu tempat mahasiswa dalam menempuh pendidikan dan mengembangkan potensi dirinya juga tidak lepas dari kehidupan kesehariannya. Tindakan prososial mahasiwa sangat beragam, terlebih adalah mahasiswa yang aktif berorganisasi dan mahasiswa yang tidak aktif berorganisasi, keduanya memiliki tingkat perilaku prososial yang berbeda. Hal ini dibuktikan dengan jurnal penelitian volume 2 No.2, Tahun 2013 yang dilakukan oleh Triyanto dan Sukmawati dengan judul "Perbedaan Perilaku Prososial antara Mahasiswa yang Aktif di Organisasi Kemahasiswaan Fakultas Ilmu Pendidikan Universitas Negeri Surabaya", hasil penelitian tersbut menghasilkan kesimpulan bahwa ada perbedaan perilaku prososial antara mahasiswa yang aktif berorganisasi dengan yang tidak aktif berorganisasi, dimana mahasiswa yang aktif berorganisasi memiliki perilaku prososial yang lebih tinggi dibandingkan dengan mahasiswa yang tidak aktif berorganisasi".

Organisasi Kemahasiswaan (Ormawa) sendiri merupakan bagian dari kelompok social yang dapat membentuk prososial mahasiswa. Desmita (2017:255) mengemukakan bahwa agen-agen sosialisasi dapat mengembangkan perilaku prososial. Agen-agen social tersebut adalah orang tua, teman sebaya dan televisi. Teman sebaya adalah agen sosialisasi yang berimplikasi jelas dengan Ormawa karena dalam Ormawa sendiri beranggotakan individu dengan usia yang hampir sama dan memiliki karakteristik yang berbeda.

Menurut Staub dalam Dayakisni dan Hudaniah (2015:162) terdapat beberapa faktor yang mendasari seseorang dalam melakukan prososial, yaitu : Self-Gain: harapan seseorang untuk memeperoleh atau menghindari sesuatu, misalnya ingin mendapatkan pengakuan, pujian atau takut dikucilkan, Personal values and norms: adanya nilai-nilai dan norma social yang diinternalisasikan oleh individu selama mengalami sosialisasi dan sebagian nilai-nilai serta norma tindakan tersebut berkaitan dengan tindakan prososial, seperti berkewajiban menegakkan kebenaran dan keadilan serta adanya norma timbal balik, Empathy: kemampuan seseorang untuk ikut merasakan perasaan orang lain.

Faktor inilah yang memunculkan perilaku prososial dari masing-masing individu dalam Ormawa. Penelitian yang dilakukan oleh Hafiza (2019) menghasilkan bahwa konformitas teman sebaya memiliki hubungan yang positif dengan sikap siswa terhadap perilaku prososial, yang berarti apabila konformitas teman sebaya meningkat maka sikap siswa terhadap perilaku prososial akan meningkat juga, begitu pula sebaliknya. Hasil tersebut menunjukkan bahwa tingkat konformitas dari masing-masing individu dalam satu wadah mempengaruhi tingkat perilaku prososialnya.

Perilaku prososial perlu dimiliki oleh mahasiswa. Hal ini beralaskan bahwa sejatinya yang tertanam pada masyarakat jika mahasiswa adalah Agent of Change. Anwar (2013) menyebutkan bahwa (Agent of Change) adalah individu atau seseorang yangbertugas mempengaruhi terget/sasaran perubahan agar mereka mengambil keputusan sesuai dengan arah yang dikehendaki. Ini artinya mahasiswa diharapkan akan 
memberikan perubahan lebih baik pada masyarakat, baik itu dalam segi tatanan maupun kehidupan masyarakat. Dengan kata lain sifat seperti: peduli, empati, kritis dan kreatif serta bersedia membantu orang lain perlu dimiliki oleh mahasiswa dalam melakukan perubahannya.

Organisasi Pergerakan Mahasiswa Islam Indonesia Universitas Negeri Semarang (PMII UNNES) merupakan Ormawa yang ada dalam sekitar wilayah UNNES. Hampir sama dengan Ormawa lainnya di dalam PMII UNNES memiliki pengurus yang kesemuanya adalah mahasiswa. Dari hasil pengamatan, dalam organisasi PMII UNNES juga memiliki fenomena perilaku prososial diantara para penguruspengurusnya, terlebih yang terlihat ketika menjalankan program kerjanya, sebagai contoh: melakukan kegiatan santunan anak yatim, pemberian korban bencana alam, pendampingan pada korban penggusuran, pemberian bantuan pada mahasiswa yang terkendala Uang Kuliah Tunggal (UKT), meramaikan dan ikut andil dalam acara warga setempat, dan lain sebagainya. Dari seluruh kegiatan yang ada bisa diamati bahwa pengurus PMII UNNES menjalankan kegiatannya tanpa meminta imbalan apapun, bahkan terkadang melakukakn iuran secara cuma-cuma demi menjalankan kegiatannya. Oleh karena itu, keaktifan berorganisasi dianggap memiliki hubungan dengan tingkat perilaku prososial. Hal ini beralaskan bahwa karena adanya tanggung jawab sebagai pengurus yang aktif berorganisasi maka kewajiban dalam menjalankan tanggung jawabnya akan dikerjakan dengan sebaik-baiknya meskipun terkadang harus sedikit berkorban. Dan hal inilah yang secara tidak langsung akan mempengaruhi tingkat perilaku prososialnya.

Akan tetapi hasil pengamatan peneliti menyatakan bahwa tidak sepenuhnya menunjukkan bahwa seluruh pengurus memiliki perilaku prososial yang tinggi. Namun masih ada pengurus yang belum secara penuh mengaplikasikan nilai-nilai organisasi itu di luar organisasi sendiri seperti: kejujuran, empati, bekerja sama, berbagi, dan menolong orang lain. Mereka cenderung ikut aktif seperti karena adanya paksaan, tujuan khusus dan atau hanya sebatas ikut-ikutan. Dengan begitu bisa disimpulkan bahwa tingkat perilaku prososial masing-masing pengurus PMII UNNES beragam.

Berdasarkan fenomena di atas penelitian ini bertujuan untuk mendiskripsikan gambaran keaktifan berorganisasi mahasiswa pengurus PMII UNNES, mendiskripsikan gambaran tingkat prososial mahasiwa pengurus PMII UNNES, dan mengetahui hubungan antara keaktifan berorganisasi dengan tingkat perilaku prososial mahasiswa pengurus PMII UNNES.

\section{METODE}

Jenis penelitian ini adalah penelitian deskriptif kuantitatif korelasional. Soesilo (2018) menyatakan bahwa penelitian korelasional merupakan penelitian yang mempunyai tujuan untuk menyelidiki atau membuktikan sejauh mana keterkaitan atau keeratan hubungan antara variable satu dengan variable yang lain.

Variabel dalam penelitian ini dapat diuraikan sebagai berikut:

a. Variabel bebas atau independent variable (X) adalah variable yang mempengaruhi variable lainnya. Dalam penelitian ini adalah keaktifan berorganisasi

b. Variabel terikat atau dependent variable $(\mathrm{Y})$ adalah variable yang dipengaruhi oleh variable bebas. Dalam penelitian ini adalah tingkat perilaku prososial

Populasi dalam penelitian ini adalah seluruh mahasiswa pengurus PMII UNNES tahun 2020 yang terdiri dari 63 mahasiswa. Teknik sampling yang digunakan adalah menggunakan Teknik sampling jenuh.

Teknik pengumpulan data yang digunakan dalam penelitian ini adalah menggunakan Teknik metode skala. Skala terdiri dari 2 jenis, yaitu skala keaktifan berorganisasi dan skala prososial.

Untuk mengukur skala prososial menggunakan skala yang dibuat berdasarkan aspek-aspek perilaku prososial yang dikemukakan oleh Mussen dalam Dayakisni dan Hudaniah (2015), yaitu: Berbagi (Sharing), Kerjasama (Cooperative), Menyumbang (donating), Menolong (Helping), Kejujuran (Honesty), dan Kedermawanan (generosity). Sedangkan untuk mengukur skala keaktifan berorganisasi menggunakan skala yang dibuat berdasarkan ciri-ciri keaktifan berorganisasi yang dikemukakan oleh Priambodo dalam Leny \& Tommy (2006), yaitu: Mahasiswa terlibat dalam kepengurusan harian maupun kepanitiaan, Sering dudukduduk dan berbincang-bincang di ruang atau kantor organisasi kemahasiswaan yang diikuti mengenai organisasi maupun isu-isu luar organisasi atau masyarkat, Menggunakan waktunya untuk kegiatan non- 
akademis, dan Anggota maupun pengurus memiliki wawasan luas tentang perkembangan dunia luar maupun tentang hal-hal seputar kampus.

Instrumen penelitian yang digunakan dalam penelitian ini menggunakan skala Likert yang memiliki 5 jawaban dimana responden akan diminta untuk menyatakan kesetujuan atau ketidaksetujuan terhadap isi pernyataan dalam lima macam kategori jawaban, yaitu: Sangat Setuju (SS), Setuju (S), Kurang Setuju (KS), Tidak Setuju (TS), dan Sangat Tidak Setuju (STS). Dalam skala likert ini terdapat pernyataan favourable dan unfavourable yang nantinya akan diberi skor sebagai berikut:

\begin{tabular}{cccc}
\hline Favourable & Bobot & Unfavourable & Bobot \\
\hline Sangat Setuju & 5 & Sangat Tidak Setuju & 1 \\
Setuju & 4 & Tidak Setuju & 2 \\
Kurang Setuju & 3 & Kurang Setuju & 3 \\
Tidak Setuju & 2 & Setuju & 4 \\
Sangat Tidak Setuju & 1 & Sangat Tidak Setuju & 5 \\
\hline
\end{tabular}

Tabel 1. Skala Likert

Pengukuran skala keaktifan berorganisasi dan skala prososial menggunakan skala likert yang dikembangkan oleh Mussen (1989). Skala likert digunakan untuk mengukur sikap, pendapat dan persepsi seseorang atau sekelompok orang tentang fenomena sosial. Dengan skala likert, maka variable yang akan diukur dijabarkan menjadi indicator variable. Kemudian indikator tersebut dijadikan sebagai titik tolak untuk menyusun item-item instrument yang dapat berupa pernyataan atau pertanyaan (Sugiyono, 2016:134).

Skala likert ini terdiri dari 62 item. Item dari skala ini masing-masing berupa 31 penyataan favourable dan unfavourable yang merupakan pernyataan-pernyataan tersebut menunjukkan nilai-nilai yang ada dalam keaktifan berorganisasi dan perilaku prososial. Skoring dilakukakn dengan menjumlahkan setiap jawaban subjek sesuai dengan nilai yang telah ditentukan sebelumnya

Menurut Sugiyono (2016: 148) instrumen penelitian adalah suatu alat yang digunakan mengukur fenomena alam maupun sosial yang diamati. Dalam pengadaan instrument penelitian akan dilakukan beberapa tahap dulu sebelumnya.

Arikunto (2009: 166) menyatakan prosedur yang ditempuh dalam pengadaan instrument penelitian adalah perencanaan, penulisan butir soal, penyuntingan, uji coba, analisis hasil, revisi dan instrument jadi. Sedangkan dalam penelitian ini, penyusunan instrumen akan peneliti tempuh dengan langkah-langkah yang dapat dilihat pada bagan sebagai berikut:

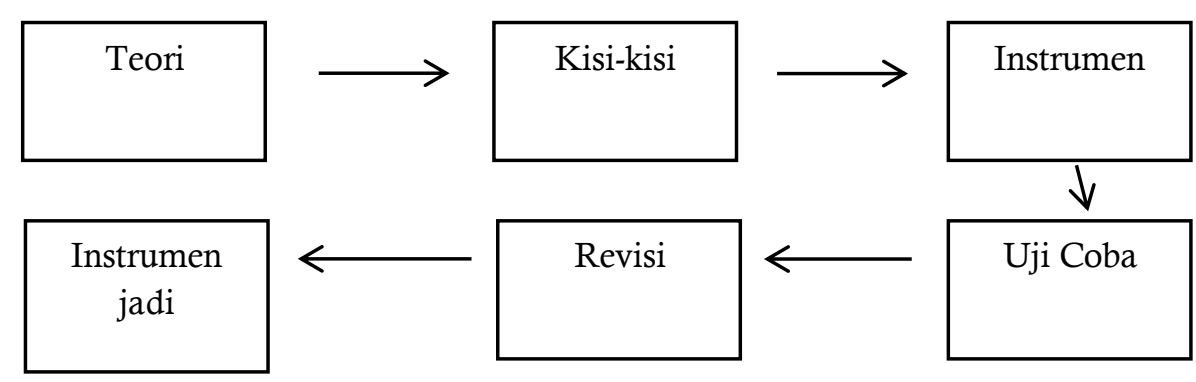

Bagan 1 Penyusunan Istrumen

Maka berdasarkan bagan tentang prosedur penyusunan intrumen di atas dapat diketahui bahwa dalam menyusun sebuah instrumen penelitian, tahapan di atas harus peneliti lewati, diantaranya yaitu menyusun kisi-kisi instrument, menyusun instrument, setelah itu diujicobakan (try out) pada responden, 
kemudian instrument direvisi untuk menghilangkan item-item yang tidak valid dan tidak reliabel. Berikutnya ketika instrument sudah diujicobakan dan sudah valid serta reliable, maka dengan begitu instrument sudah jadi dan siap digunakan dalam penelitian.

Untuk mengukur validitas soal tes yang nantinya akan digunakan dalam penelitian, peneliti menggunakan rumus korelasi momen produk (product moment) yang dikemukakan oleh Karl Pearson yaitu rumus Pearson Correlation.

Angka korelasi yang diperoleh tersebut kemudian dibandingkan dengan angka kritik tabel korelasi nilai r. Jika nilai rhitung > rtabel, maka butir valid. Sebaliknya jika nilai rhitung $<$ rtabel, maka butir tidak valid.

Dalam penelitian ini untuk mengetahui tingkat reliabilitas instrument skala psikologis maka peneliti menggunakan rumus Alpha Cronbach. Alasannya adalah karena jawaban pada kuesioner ini berbentuk skala yang jawabannya 1 sampai 5 . Adapun rumus Alpha adalah sebagai berikut:

$$
\mathrm{r}_{11}=\left[\frac{k}{k-1}\right]\left[1-\frac{\sum \sigma \cdot b^{2}}{\sigma \cdot t^{2}}\right]
$$

Rumus korelasi Product Moment:

Keterangan:

$\mathrm{r} 11=$ Reliabilitas instrumen

$\mathrm{k} \quad=$ Banyaknya butir-butir pertanyaan

$\sum \sigma . b 2=$ Jumlah Varian butir

$\sigma . b 2=$ Varian total

$\square 2 \mathrm{t} \quad$ : varian total (Arikunto, 2009:171)

Dari hasil perhitungan reliabilitas kemudian hasil tersebut dibandingkan dengan nilai rtabel dan apabila $\mathrm{r} 11 \geq$ rtabel pada taraf signifikan 5\% maka butir item dikatakan reliabel. Besar kecilnya koefisien mengidentifikasikan tentang kuat dan lemahnya hubungan yang ada. Nilai rhitung yang lebih besar dari rtabel berarti instrumen semakin berkurang reliabilitasnya. Penjelasannya adalah sebagai berikut:

\begin{tabular}{ll}
\hline Koefisien korelasi & Kriteria \\
\hline $0,91-1,00$ & Sangat Tinggi \\
$0,71-0,90$ & Tinggi \\
$0,41-0,70$ & Cukup \\
$0,21-0,40$ & Rendah \\
Negatif $-0,20$ & Sangat Rendah \\
\hline
\end{tabular}

Tabel. 2 Kriteria Korelasi

\section{HASIL}

\section{Hasil dan Pembahasan}

Berdasarkan hasil pengujian pre-test item instrumen skala prososial dengan menggunakan rumus product moment diketahui bahwa dari 62 pernyataan yang diajukan pada 34 responden diperoleh 38 pernyataan valid. Karena jumlah pernyataan valid masih belum memenuhi target yang ditentukan, maka ada 2 item tidak valid yang harus diperbaiki dengan mempertimbangkan jumlah dari masing-masing indikator agar seimbang, kemudian item yang tidak valid dan tidak terpakai dibuang, tidak digunakan dalam 
penelitian ini. Sedangkan untuk pengujian item skala prososial diketahui bahwa terdapat 34 pernyataan valid. Karena jumlah pernyataan valid masih belum memenuhi target yang ditentukan, maka ada 6 item tidak valid yang harus diperbaiki dengan mempertimbangkan jumlah dari masing-masing indikator agar seimbang, kemudian item yang tidak valid dan tidak terpakai dibuang, dan tidak digunakan dalam penelitian ini.

Setelah pre-test dan melakukan revisi pada intrumen maka langkah selanjutnya adalah melakukan post-test pada data penelitian mengenai keaktifan berorganisasi dan tingkat prososial mahasiswa pengurus PMII UNNES tahun 2020 dengan jumlah responden sebanyak 63 mahasiswa dengan jumlah item sebanyak 40. Hasil uji normalitas data dan hasil product moment menunjukkan data sebagai berikut:

Tabel 2.1

Hasil uji normalitas data

One-Sample Kolmogorov-Smirnov Test

Unstandardized

Residual

$\mathrm{N}$

Normal Parameters ${ }^{\mathrm{a}, \mathrm{b}}$

Mean

0E-7

Std. Deviation

11.62309534

Absolute

Most Extreme Differences

Positive

Negative

Kolmogorov-Smirnov Z

Asymp. Sig. (2-tailed)

.915

a. Test distribution is Normal.

b. Calculated from data.

Tabel 2.2

Hasil Analisis Uji Hubungan Antara Keaktifan Berorganisasi dengan Tingkat Perilaku Prososial Mahasiswa 


\begin{tabular}{|c|c|c|c|}
\hline \multicolumn{4}{|c|}{ Correlations } \\
\hline & & Keaktifan & Prososial \\
\hline \multirow{3}{*}{ Keaktifan } & Pearson Correlation & 1 & $.512^{* *}$ \\
\hline & Sig. (2-tailed) & & .000 \\
\hline & $\mathrm{N}$ & 63 & 63 \\
\hline \multirow{3}{*}{ Prososial } & Pearson Correlation & $.512^{* *}$ & 1 \\
\hline & Sig. (2-tailed) & .000 & \\
\hline & $\mathrm{N}$ & 63 & 63 \\
\hline **. Correl & on is significant at th & .01 level $(2-1$ & ailed). \\
\hline
\end{tabular}

Hasil uji normalitas dengan menggunakan bantuan program SPSSS 20 diperoleh koefisien K-SZ sebesar 0,557 dengan nilai signifikansi (p) sebesar 0,915. Hal ini menunjukkan bahwa $\mathrm{p}>$ 0,05 sehingga dapat dikatakan bahwa data berdistribusi normal. Sedangkan hasil uji hipotesis menggunakan rumus korelasi product moment dari Pearson. Diketahui bahwa koefisien korelasi (r) keaktifan berorganisasi dengan tingkat perilaku prososial dengan rhitung $=0,512$. Bila dibandingkan dengan rtabel dengan signifikansi 5\% dengan $\mathrm{N}=63$, maka diperoleh rtabel $=0,244$. Dengan demikian rhitung > rtabel, maka hipotesis no (Ho) yang menyatakan "tidak ada hubungan yang positif dan signifikan antara hubungan keaktifan berorganisasi dengan tingkat perilaku prososial mahasiswa pengurus PMII UNNES" ditolak. Sedangkan hipotesis alternative (Ha) yang berbunyi "ada hubungan yang positif dan signifikan antara hubungan keaktifan berorganisasi dengan tingkat perilaku prososial mahasiswa pengurus PMII UNNES" diterima.

Berdasarkan hasil perhitungan korelasi menggunakan rumus product moment diperoleh nilai koefisien korelasi (rhitung) sebesar 0,512 maka nilai koefisien korelasinya adalah korelasi positif, karena tiap-tiap kenaikan nilai variable X (keaktifan berorganisasi) selalu disertai kenaikan yang seimbang pada nilai-nilai variable Y (tingkat keaktifan berorganisasi mahasiswa). Perolehan koefisien korelasi sebesar 0,512 jika dikonversikan dengan table interpretasi " $r$ " termasuk dalam kategori sedang atau memiliki korelasi sedang. Dengan demikian dapat disimpulkan bahwa ada hubungan yang positif dan signifikan antara keaktifan berorganisasi dengan tingkat perilaku prososial mahasiswa pengurus PMII UNNES 2020.

\section{KESIMPULAN}

Berdasarkan hasil analisis dari pembahasan, maka disimpulkan bahwa terdapat hubungan positif yang signifikan antara mahasiswa yang aktif berorganisasi dengan tingkat perilaku prososial mahasiswa. Sehingga bisa dimaknai bahwa jika mahasiswa aktif berorganisai, maka mahasiswa tersebut memiliki perilaku prososial yang tinggi. Hal ini dapat diketahui dari hasil analisis uji korelasi product moment diperoleh rhitung 0,512 > rtabel 0,244. Lalu signifikasinya adalah sebesar 0,915 , sehingga $p>0,05$ yang dapat dikatakan data berdistribusi normal yang artinya adalah ada hubungan yang positif dan signifikan antara keaktifan berorganisasi dengan tingkat perilaku prososial mahasiswa pengurus PMII UNNES 2020 


\section{DAFTAR PUSTAKA}

Anwar, Syaiful. (2013). Agen Perubahan (Agent of Change). Pusdiklat Bea dan Cukai

Arikunto, Suharsimi. 2009. Prosedur Penelitian Suatu Pendekatan Dan Praktik. Jakarta: Rineka Cipta

Baron, R. A., \& Branscombe N.R. Social Pshychology 13th Edition. (2012). United States of America: Pearson Education

Dayakisni, T., \& Hudaniah. (2009). Psikologi Sosial. Malang: Universitas Muhamadiyah Malang Press

Desmita. (2017). Psikologi Perkembangan Peserta Didik. Bandung: PT Remaja Rosdakarya

Hafiza, N. (2019). Hubungan Konformitas Teman Sebaya Dengan Sikap Siswa Terhadap Perilaku Prososial. Jurnal Consilium: Berkala Konseling dan Ilmu Keagamaan. 6 (1), 28-34

Mahmudah, S. (2010). Psikologi Sosial: Sebuah Pengantar. UIN-Maliki Press, Malang.

Soesilo, T.D. (2018). Penelitian Inferensial dalam Bidang Pendidikan. Salatiga: Satya Wacana University Press.

Sugiyono. 2016. Metode Penelitian Pendidikan. Bandung: Alfabeta.

Triyanto, S., \& Sukmawati, P. (2013). Perbedaan Perilaku Prososial antara Mahasiswa yang Aktif dengan Mahasiswa yang Tidak Aktif Di Organisasi Kemahasiswaan Fakultas Ilmu Pendidikan Universitas Negeri Surabaya. Jurnal Character. Jurnal Character. 2 (2), 1-7 